Milena BOGDANOVIĆ, Ph.D.

Teacher Training Faculty in Vranje

University of Niš
УДК 519.17

- оригинални научни рад -

\title{
SOME REMARKS ON THE $\pi$-DIRECTABLE AUTOMATA AND DEFINITE AUTOMATA: A SURVEY
}

\begin{abstract}
The concept of $\pi$-directable automata is a concomitant specialization concept of the directable automata and generalization of the concept definite automata. The main purpose of this survey is to describe certain properties of $\pi$ directable and definite automata. These are mainly algebraic and structural properties, as well as the properties of their transition semigroups. Various specializations and generalizations of directable automata are an interesting field of Automata theory. They have useful applications in industrial context and still offer open questions. There are applications in the fields of many-valued logics, biocomputing, set theory, etc.
\end{abstract}

Key words: $\pi$-directable automata, definite automata, nilpotent automata, transition semigroups.

\section{Introduction and basic concepts}

Directable automata (or synchronizable, cofinal, reset automata) were introduced in a paper by Černý 1964 [3]. Many authors are investigated some of their special types even several years earlier (definite automata were studied in 1956 by Kleene and in 1963 by Perles, Rabin and Shamir, nilpotent automata were investigated in 1962 by Shevrin, etc). Reverse definite automata and languages were studies in 1963 by Brzozowski and in 1966 by Ginsburg. As a common generalization of definite automata and reverse definite automata, generalized definite automata were introduced in 1966 by Ginsburg, and they were also suited in 1969 by Steinby.

Various other specializations and generalizations of the directable automata have appeared recently (in the paper by Petković, Ćirić and Bogdanović, Ćirić, Imreh, Petković and Steinby, Popović, Bogdanović, Petković and Ćirić, Bogdanović M., [4,5,6,7] etc).

Now, we give the definitions of dirctable automata and its special types ( $u$-directable automata, $k$-definite, trap- $u$-directable and trapped automata, $k$ nilpotent, $\pi$-directable).

The automata considered throughtout the paper are automata without outputs, in the sense of the definition given by F. Gécseg and I. Peák in [9], and we call them simply automata.Therefore, an automata is defined as a triple 
$(A, X, \delta)$, where $A$ and $X$ are non-empty sets, not necessarily finite. $A$ is called the set of states and $X$ is called the input alphabet, and $\delta: A \times X \rightarrow A$ is the transition function of this automata. All automata that will be cinsidered in the paper will have the same input alphabet $X$ with $|X| \geq 2$.

The free monoid an the free semigrup over $X$ are denoted by $X^{*}$ and $X^{+}$, respectively. The length of a word $u \in X^{*}$ denoted by $|u|$. For any $k \in N^{0}$, the subsets $X^{k}, X^{\leq k}$ and $X^{\geq k}$ of $X^{*}$ are defined by $X^{k}=\left\{u \in X^{*}|| u \mid=k\right\}, X^{\leq k}=$ $\left\{u \in X^{*}|| u \mid \leq k\right\}$ and $X^{\geq k}=\left\{u \in X^{*}|| u \mid \geq k\right\}$.

Under the action of an input word $u \in X^{*}$, the automata $A$ goes from a state $a$ into the state denoted by $a u$.

An automata $A$ is called $u$-directable for a given word $u \in X^{*}$ if $a u=b u$, for all $a, b \in A$. In that case the word $u$ is called directing word of $A$. Futhermore, for automata $A$ is said to be directable if there exists a word $u \in X^{*}$ such taht $A$ is $u$-directable. We may say that the directing word $u$ directs the states of the automata $A$ into a single state that will be called a $u$-neck of $A$ and denoted by $d_{u}$. A state $d \in A$ is called a neck of $A$ if there exists $u \in X^{*}$ such thatr $d$ is a $u$-neck of $A$.

Now, we will give two ways to specialize notation of a directable automata. First, for a given number $k \in N_{0}$, an automata $A$ is called $k$-definite if each word from $X^{\geq k}$ is a directing word of $A$. An automata $A$ is said to be definite if there exists $k \in N_{0}$ such that $A$ is $k$-definite. The smallest number $k \in N_{0}$ for which $A$ is $k$-definite is called the degree of definiteness of $A$. The 1-definite automata is called reset automata.

Furthemore, if $u \in X^{*}$ such that $A$ is $u$-directable and as a trap $a_{0}$, then $a_{0}$ is both the unique trap and the unique neck of $A$. In this case the word $u$ directs the states of $A$ into to trap $a_{0}$ and the automata $A$ is called trap- $u$-directable, since the word $u$ is called a trap-directing word of $A$. Similary, an automata $A$ is said to be trap-directable if there exists a word $u \in X^{*}$ such that $A$ is trap- $u$-directable.

We can give a common specialization of the notions of definite and trapped automata. Namely, for a given number $k \in N_{0}$, an automata $A$ is called $k$-nilpotent if each word from $X^{\geq k}$ is a trap-directing word of $A$. Equivalently, $A$ is called $k$-nilpotent if $A$ is $k$-definite and has a trap. An automata $A$ is said to be nilpotent if there exists a number $k \in N_{0}$ such that $A$ is $k$-nilpotent. The smallest number $k \in N_{0}$ for which $A$ is $k$-nilpotent is called the degree of nilpotency of $A$.

In a similar way the notion of a trap-directable automata and a nilpotent automata can be generalized. Namely, for a given word $u \in X^{*}$ an automata is called $u$-trapped if $a u \in \operatorname{Tr}(A)$, for all $a \in A$. In this case the word $u$ is called a trapping word of $A$. An automata $A$ is called a trapped automata if there exists a word $u \in X^{*}$ such that $A$ is $u$-trapped. Firthemore, an automata $A$ is said to be reverse $k$-definite if, for given number $k \in N_{0}$, every word from $X^{\geq k}$ is a trapping word of $A$. An automata $A$ is said to be reverse definite if there exists $k \in N_{0}$ such that $A$ is reverse $k$-definite. 
On this basis, it is obvious that, for some $u \in X^{*}$, an automata $A$ is trap$u$-directable if and only if it is $u$-directable and $u$-trapped. As well, we have that $A$ is $k$-nilpotent if and only if it is $k$-definite and reverse $k$-definite, for $k \in N_{0}$.

Labeling of certain types of automata will be taken from the article [2] of which were given many important characterization of the transition semigroups of the automata.

Automata be referred the $\pi$-directable automata if for each input word $u \in X^{+}$there is $k \in N$ so that there is $u^{k} \in D W(A)$. Similarly, if for each input word $u \in X^{+}$there is $k \in N$ so that $u^{k} \in \operatorname{LDW}(A), u^{k} \in G D W(A), u^{k} \in$ $\operatorname{TDW}(A), u^{k} \in \operatorname{LTDW}(A), u^{k} \in T W(A)$, then we call the automata $A$ the locally- $\pi$-directable automata, the general $\pi$-directable automata, the trap- $\pi$ directable automata, the uniformly locally trap- $\pi$-directable and the $\pi$-trapped automata, respectively [7].

\section{The structure and transition semigroups}

The main aim of this section is to describe the structure of the $\pi$-directable automata and definite automata considered in Section 1. This will be done using various decomposition and composition techniques. On the other hand, we also characterize these automata through certain properties of their transition semigroups.

The transition semigroup $S(A)$ of an arbitrary automata $A$ is defined as the subsemigroup of the full transformation semigroup of the set of states of $A$ consisting of the mappings of the form $u^{A}$, where $u \in X^{+}$.

Theorem 2.1. [4] The following conditions on automata $A$ are equivalent:

i. $\quad S(A)$ has a zero;

ii. $\quad A$ is a retractive extension of a discrete automata by a trapdirectable automata;

iii. $\quad A$ is a direct sum of trap-directable automata with same trapping word;

iv. A is a subdirect product of a discrete and a trap-directable automata;

v. A is a uniformly trap-directable automata;

If $A$ is a finite automata, then the condition iii. can be replaced by:

iii'. A is a direct sum of trap-directable automata.

Theorem 2.2. [4] The following conditions on automata A are equivalent:

i. $\quad S(A)$ is a nilpotenet extension of right zero band;

ii. $\quad A$ is a direct sum of definte automata with bounded degrees of definiteness;

iii. A is a uniformly locally definite automata; 
If $A$ is a finite automata, then the condition ii. can be replaced by following one:

ii'. A is a direct sum of definite automata.

The automata $A$ is called general $\pi$-directable automata if for each word $u \in X^{+}$, there is $k \in N$, so that $u^{k}$ is the general directing word, ie. $u^{k} \in G W(A)[1]$.

Lemma 2.3. [8] For an arbitrary automaton $A$, sets of $T D W(A), L T D W$ $(A), T W(A), D W(A), L D W(A)$ and $G D W(A)$ are the ideals of free monoids $X^{*}$ and holds conditions:

(i) $T D W(A) \neq \emptyset \Rightarrow \operatorname{TDW}(A)=\operatorname{LTW}(A)$

$$
=T W(A)=D W(A)=L D W(A)=G D W(A) ;
$$

(ii) $\operatorname{LTDW}(A) \neq \varnothing \Rightarrow \operatorname{LTDW}(A)=\operatorname{LDW}(A)$

$$
=T W(A)=G D W(A)
$$

(iii) $T W(A) \neq \varnothing \Rightarrow T W(A)=G D W(A)$;

(iv) $D W(A) \neq \emptyset \Rightarrow D W(A)=L D W(A)=G D W(A)$;

(v) $\operatorname{LDW}(A) \neq \emptyset \Rightarrow \operatorname{LDW}(A)=G D W(A)$.

Theorems that follow provide a variety of characteristics of $\pi$-directable automata.

Theorem 2.4. [8] For the automata $A$ the following conditions are equivalent:

(1) $A$ is generally $\pi$-directable automata;

(2) $A$ is an extension of local $\pi$-directable automata using trap $\pi$-directable automata;

(3) $S$ is a nil-extension of rectangular bands.

Proof: $(1) \rightarrow(2)$. Let the automata $A$ is generally $\pi$-directable. Then, it is the extension of the locally directable automata $B$ using trap-directable automata $C$. As the automata $B$ is locally directable, then $L D W(A) \neq \varnothing$, and based on Lemma 2.3, we have $\operatorname{LDW}(B)=G D W(B)$. Thus, for every word $u \in X^{*}$ there is $k \in N$ such that $u^{k} \in G D W(B)=L D W(B)$, and $B$ is uniformly locally $\pi$-directable automata.

On the other hand, since $C$ is the trap directable automata, it is $T D W(A) \neq \emptyset$, and by the

Lemma 2.3 it follows that $T D W(C)=G D W(C)$. Therefore, for every word $u \in X^{+}$, there exists $k \in N$, so that $u^{k} \in T D W(C)=G D W(C)$, and the automata $C$ is an trap directable automata.

This we have proved the implication $(1) \rightarrow(2)$.

(2) $\rightarrow$ (1). Let $A$ is the extension of uniformly locally $\pi$-directable automata $B$ using the trap $\pi$-directable automata $C$. Consider an arbitrary word $u \in X^{+}$. Then exist $k, l \in N$ such that $u^{k} \in L D W(B)$ and $u^{l} \in T D W(C)$. 
Based on the feature of the sets of directing words, applies $u^{k+l}=u^{k} u^{l} \in$ $G D W(A)$. Thus we have proved that $A$ is the generally $\pi$-directable automata.

$(1) \rightarrow$ (3). Notice, an arbitrary word $u \in X^{+}$. Then there exists $k \in N$ such that $u^{k} \in G D W(A)$, which means that $\eta_{u}^{k}=\eta_{u^{k}}$ is an bi-zero in $S(A)$. Let $E$ be the set of all-zero of $S(A)$. Then we have that $E$ is a rectangular bar and the ideal of $S(A)$, and how we proved that for every $\eta_{u} \in S(A)$ there exists $k \in N$ such that $\eta_{u}^{k} \in E$, this conclude that the $S(A)$ is the nil-extensions of rectangular bands $E$.

$(3) \rightarrow(1)$. Let $S(A)$ is the nil-extensions of rectangular bands $E$. Consider arbitrary word $u \in X^{+}$. By assumption, there exists $k \in N$ such that $\eta_{u}^{k} \in E$, ie. $\eta_{u^{k}} \in E$. This means that $\eta_{u^{k}}$ is the bi-zero of $S(A)$, which implies that the $u^{k} \in G D W(A)$. Thus we have proved that $A$ is the generally $\pi$-directable automata.

This is proof of the theorem is complete.

Let $A$ is the $\pi$-directable automata. Then, for each word $u \in X^{+}$is there $n \in N$ so that is $u^{n} \in D W(A)$. The smallest number $n \in N$ such that $u^{n} \in$ $D W(A)$, is the level of directing word $u$. Clearly, the directing words of the automata $A$ have the same level of guidance 1 .

Following theorems are fully proven in [1].

Now we describe the uniformly locally trap- $\pi$-directable automata.

Theorem 2.5. [8] For the automata $A$ the following conditions are equivalent:

(1) $A$ is uniformly locally $\pi$-directable automata;

(2) $A$ is the direct sum of $\pi$-directable automata, $A_{\alpha}, \alpha \in Y$ and every word $u \in X^{+}$has a limited level of guidance in automata $A_{\alpha}, \alpha \in Y$;

(3) $S(A)$ is a nil-extension right zero bands.

Automata $A$ is the $\pi$-trapped, if for each word $u \in X^{+}$, for which there is $k \in N$, hold $u^{k} \in T W(A)$.

The next theorem describes, among other things, the structure of the transition semigroup of the $\pi$-trapped automata.

Theorem 2.6. For the automata $A$ the following conditions are equivalent:

1) $A$ is the $\pi$-trapped automata;

2) $A$ is an extension of discrete automata with trap $\pi$-directable automata;

3) $A$ is a nil-extension of left zero bands.

The following theorem gives a complete characterization of uniformly locally trap $\pi$-directable automata. 
Theorem 2.7. For the automata $A$ the following conditions are equivalent:

1) $A$ is uniformly locally trap $\pi$-directable automata;

2) $A$ is the extension retractiveof the discrete automata with the trap $\pi$ directable automata;

3) $A$ is the direct sum of trap $\pi$-directable automata, $A_{\alpha}, \alpha \in Y$ and every word $u \in X^{+}$has a limited level of guidance in automata $A_{\alpha}, \alpha \in Y$;

4) $A$ is the product subdirect of a discrete automata and a trap $\pi$-directable automata;

5) $A$ is the parallel composition of a discrete automata, and a trap $\pi$ directable automata;

6) $S(A)$ is a nil-semigroup.

\section{Correlation between $\pi$-directable automata and definite automata}

In the case of finite automata is no difference between the $\pi$-directable automata and the definite automata. The following theorem proves just that.

Theorem 3.1. [8] The finite automata $A$ is a trap $\pi$-directable automata if and only if it is nilpotent automata.

Proof: Let the automata $A$ is the trap $\pi$-directable automata. This means that there is a state $a_{0} \in A$, so that for all $a \in A$ and for every word $u \in X^{+}$, for which there is $n \in N$ such that $u^{n} \in D W(A)$, holds $a u=a_{0}$. The transition semigroup $S(A)$ of the automata $A$ is a nil-semigroup. On the other hand, $A$ is a finite automata, so the transition semigroup $S(A)$ is finite. Any finte nil-semigroup is nilpotent, and then $S(A)$ is nilpotent semigroup. The automata $A$ is the direct sum of the automata nilpotent $A_{\alpha}, \alpha \in Y$. However, $A$ is the trap-directable automata, and it is the indecomposable of the direct sum. This means that $|Y|=1$, ie. $Y=\{a\}$, and $A=A_{a}$. So, $A$ is the nilpotent automata.

The reversal of the theorem is clear.

The proof that a finite automata who is the $\pi$-directable, it is also definite, given the following theorem.

Theorem 3.2. [8] The finite automata $A$ is a $\pi$-directable automata if and only if it is definite automata.

Proof: Let the automata $A$ is the $\pi$-directable automata. Then, $A$ is a locally $\pi$-directable automata and the transition semigroup of the automata $A$ is nil-extension of the right zero bands. However, as $A$ is a finite automata, then $S(A)$ is finite semigroup, so it must be a nilpotent extension of right zero bands. From this fact it follows that $A$ is a direct sum of the automata definite, with the same degree of definiteness. Furthermore, the automata $A$ is indecomposable in direct sum, because it is the $\pi$-directable, so it must be an automata definite.

The reversal of the theorem is clear.

We can prove that there is equivalence between generally $\pi$-directable and general definite automata, as the uniformly locally $\pi$-directable and uniformly locally definite with analogous considerations [8]. 


\section{Conclusion}

Automata are the prime examples of general computational systems over discrete spaces and have a long history both in theory and application.

Directable automata, known also as synchronizable, cofinal and reset automata, are a significant type of automata with very interesting algebraic properties and important applications in various branches of Computer Science. The automata are viewed as systems that can be used for processing and transmission of certain kinds of information. Sixties and later, there is a considerable number of books on the Theory of Automata, which resulted in the development of this area as one of the most important in the field of Computer Science.

Finite automata are important in science, mathematics, and engineering. Engineers like them because they are superb models for circuits. Computer scientists adore them because they adapt very nicely to algorithm design, for example the lexical analysis portion of compiling and translation. Mathematicians are intrigued by them too due to the fact that there are several nifty mathematical characterizations of the sets they accept.

\section{References}

[1] M. Bogdanović, Directable Automata, Their Generalizations and Specializations (Direktabilni automati, njihova uopštenja i specijalizacije), (in Serbian), MSc thesis, University of Niš, Faculty of Sciences and Mathematics, 2001.

[2] S. Bogdanović, B. Imreh, M. Ćirić and T. Petković, Directable automata and their generalizations - A survey, in: S. Crvenkovic and I. Dolinka (eds.), Proc. VIII Int. Conf. "Algebra and Logic" (Novi Sad, 1998), Novi Sad Journal of Mathematics 29 (2) (1999), pp. 31-74.

[3] J. Černý, Poznámka $k$ homogénym experimentom s konecinými automatami, Mat.-fyz. cas. SAV 14 (1964), pp. 208-215.

[4] T. Petković, M. Ćirić and S. Bogdanović, Decompositions of automata and transition semigroups, Acta Cybernetica (Szeged) 13 (1998), pp. 385-403.

[5] Ž. Popović, S. Bogdanović, T. Petković, and M. Ćirić, Trapped automata, Publicationes Mathematicae Debrecen 60 (3-4) (2002), pp. 661-677.

[6] Ž. Popović, S. Bogdanović, T. Petković, and M. Ćirić, Generalized directable automata, in: Words, languages and combinatorics, III, Proceedings of the Third International Colloquium in Kyoto, Japan, (M. Ito and T. Imaoka, eds.), World Scientific, (2003), pp. 378-395.

[7] M. Bogdanović, M. Ćirić, T. Petković, Necks of automata, Novi Sad, Journal of Mathematics, 34, No. 2, (2004), pp. 5-15, ISSN: 1450-5444

[8] M. Bogdanović, On finite $\pi$-directable automata, International Journal of Applied Mathematics and Computation, Volume 3(4), (2011), pp. 256-259, http://ijamc.psit.in ISSN 0974 - 4665 (print version) ISSN 0974 - 4673 (electronic version)

[9] F. Gécseg, I. Peák, Algebraic Theory of Automata, Akadémiai Kiadó, Budapest, 1972. 
Доц. др Милена Богдановић

\section{О НЕКИМ СВОЈСТВИМА $\pi$-ДИРЕКТАБИЛНИХ И ДЕФИНИТНИХ АУТОМАТА: ПРЕГЛЕД}

Сажетак: Појам л-директабилних аутомата представља истовремено специјализацију појма директабилних аутомата и генерализацију појма дефинитних аутомата. Основна идеја овог рада је да се опишу нека својства л-директабилних аутомата и дефинитних аутомата. Та својства се односе, пре свега на неке њихове алгебарске и структурне особине, као и на особине юихових полугрупа прелаза. Различите специјализачије и генерализације директабилних аутомата представљају веома занимљиву област Теорије аутомата. Они имају различите примене у индустрији и технологији и још увек нуде многа отворена питања. Налазе примену у вишевредносним логикама, биорачунарству, теорији скупова, итд.

Кључне речи: $\pi$-директабилни аутомати, дефинитни аутомати, нилпотентни аутомати, полугрупе прелаза.

Примљено: 17. 8. 2014. године.

Одобрено за штампу: 12. 1. 2015. године. 